\section{Original Article}

Check for updates

\section{OPEN ACCESS}

Received: Mar 8, 2020

Accepted: Oct 19, 2020

*Correspondence to

Pakit Vichyanond

Emeritus Professor of Pediatrics, Samitivej

Allergy Institute (SAI), 337 Somdej Prachao

Taksin Road, Samitivej Thonburi Hospital,

Bangkok 10600, Thailand.

Tel: +66-2-418-0011

+66-81-407-1589

E-mail: pakitv@gmail.com

Copyright (c) 2020. Asia Pacific Association of Allergy, Asthma and Clinical Immunology.

This is an Open Access article distributed under the terms of the Creative Commons Attribution Non-Commercial License (https:// creativecommons.org/licenses/by-nc/4.0/) which permits unrestricted non-commercial use, distribution, and reproduction in any medium, provided the original work is properly cited.

ORCID iDs

Chulamanee Wongteerayanee (iD)

https://orcid.org/0000-0003-2467-9313

Pattara Tanticharoenwiwat (D)

https://orcid.org/0000-0002-6685-838X

Nuntanut Rutrakool iD

https://orcid.org/0000-0003-1190-5115

Anchalee Senavonge (iD)

https://orcid.org/0000-0002-8294-3496

Nivat Jeekungwal (iD)

https://orcid.org/0000-0001-6609-8811

Punchama Pacharn (iD

https://orcid.org/0000-0002-2507-2057

Pakit Vichyanond (iD)

https://orcid.org/0000-0001-5103-2916

Conflict of Interest

\title{
Feasibility of a 3-step protocol of wheat oral immunotherapy in children with severe wheat allergy
}

\author{
Chulamanee Wongteerayanee (1) ', Pattara Tanticharoenwiwat (1) ', \\ Nuntanut Rutrakool (1) ', Anchalee Senavonge (1) ', Nivat Jeekungwal (1) ', \\ Punchama Pacharn (iD) 1,2, and Pakit Vichyanond (1) 1,2,*
}

'Samitivej Allergy Institute (SAI), Samitivej Thonburi Hospital, Bangkok, Thailand

${ }^{2}$ Department of Pediatrics, Faculty of Medicine Siriraj Hospital, Bangkok, Thailand

\section{ABSTRACT}

Background: Wheat allergy is not an uncommon event among Thai children. Despite strict avoidance, some patients developed reactions after accidental exposure to minute amount of wheat and thus disturbed their quality of life. Wheat oral immunotherapy (OIT) has been reported to be an alternative treatment for such patients.

Objective: We designed a new 3-step wheat OIT protocol for treatment of severe wheat allergy in Thai patients. The feasibility of the protocol is evaluated and is reported here in this paper. Methods: We retrospectively reviewed medical records of 26 patients who had undergone wheat OIT during a 30-month period. The 3-step protocol consisted of an initial phase of double-blind, placebo-controlled food challenge (DBPCFC) and initiation of OIT, a build-up phase, and a maintenance phase. Patient retention in the protocol was the main outcome for this feasibility study. Adverse effects during OIT were recorded. Correlation between serum specific IgE (SpIgE) to wheat and eliciting dose in phase I was determined.

Results: Fourteen females and 12 males with a median age of 6 years were studied. Their median age when wheat allergy began was 8 months. Median SpIgE to wheat was high (198 $\mathrm{kU}_{\mathrm{A}} / \mathrm{L}$ ). All patients developed reactions during DBPCFC with 17 of 26 patients had moderate to severe reactions required adrenaline injections. Median of eliciting dose of wheat was exceedingly low, i.e., $20 \mathrm{mg}$ of wheat protein. At the end of the study, 23 of 26 patients (88\%) were still in the study. Adverse reactions during the build-up phase was frequent (13 patients, $50 \%$ ), with adrenaline required in 6 occasions. Six patients reached maintenance phase. Conclusion: The new 3-step wheat OIT protocol was feasible in these highly wheat-sensitized patients. Despite a high retention rate, a high rate of adverse effects was observed both during DBPCFC and build-up phases.

Keywords: Food allergy; Wheat; Wheat hypersensitivity; Oral immunotherapy; Child

\section{INTRODUCTION}

IgE-mediated reactions to wheat, particularly anaphylaxis and exercise-induced anaphylaxis has been increasingly observed worldwide [1]. In Japan, wheat allergy has become the third leading cause of anaphylaxis in children following egg and cow's milk [2]. Elsewhere in Asia, reports of wheat allergy came from countries such as Thailand [3, 4], Korea [5], China [6, 7], 
The authors have no financial conflicts of interest.

Author Contributions

Conceptualization: Chulamanee Wongteerayanee, Punchama Pacharn, Pakit Vichyanond. Data curation: Chulamanee Wongteerayanee, Pattara Tanticharoenwiwat, Nuntanut Rutrakool, Anchalee Senavonge. Formal analysis: Chulamanee Wongteerayanee, Pakit Vichyanond. Funding acquisition: Chulamanee Wongteerayanee, Nivat Jeekungwal, Pakit Vichyanond. Methodology: Chulamanee Wongteerayanee, Pakit Vichyanond. Project administration: Pakit Vichyanond. Visualization: Pakit Vichyanond. Writing - original draft: Chulamanee Wongteerayanee, Pakit Vichyanond. Writing review \& editing: Pakit Vichyanond. and Iran [8]. Paucity of reported cases from Hong Kong [9] and Singapore [10] could be due to differences in food selections and food preparation in their daily lives. In Thailand, onset of wheat allergy is primarily observed among infants around 1-2 years of age [11]. Remission of wheat allergy can occur among patients with low degree of wheat sensitization $[3,12,13]$. In highly wheat-sensitized patients, especially those with wheat specific $\operatorname{IgE}(\mathrm{SpIgE}) \geq 50$ $\mathrm{kU}_{\mathrm{A}} / \mathrm{L}$, remission was uncommon [12]. Oral immunotherapy (OIT) to wheat among these individuals has been tried with good results as noted in reports from several countries around the world $[8,14-16]$. OIT has been shown to reduce reactions after accidental exposure to a small amount of wheat and eventually to a complete oral tolerance, i.e., sustained unresponsiveness [16]. Various schedules of wheat OIT have been reported with varying degree of success [8,14-17]. Sato et al. [15] reported a high degree of success (over $60 \%$ ) using a rush protocol to reach $5.2 \mathrm{~g}$ of wheat protein. Similarly, a report from Spain indicated that rush OIT to wheat can be performed successfully in 4 out of 6 children with few adverse effects [14]. Our group reported a successful semi-rush protocol for wheat OIT in 2 very highly wheat-sensitized patients [4]. Systemic reactions requiring several adrenaline injections were observed indicating that there was a need for a modification of protocol for our population. We, therefore, devised a new 3-phase protocol for wheat OIT for use in our patients with high degree of wheat sensitivity. In this report, we described the feasibility of the protocol during its first 30-month period at our institution.

\section{MATERIALS AND METHODS}

\section{Type of study}

The study was a retrospective review of medical records of patients underwent wheat OIT at Samitivej Allergy Institute (SAI) from January 1, 2016 to June 30, 2018.

\section{Patients}

Patients enrolled into the study were 26 children with severe wheat allergy. They presented with allergic manifestations such as generalized urticaria and angioedema, respiratory involvement (rhinorrhea, wheezing), abdominal symptoms (abdominal pain, vomiting), and alteration of consciousness. Their ages were over 2 years of age. All patients had positive SpIgE to wheat over $0.35 \mathrm{kU} / \mathrm{L}$ (Thermo-Fisher, Uppsala, Sweden). Skin prick test to wheat extracted in $10 \%$ alcohol was performed in 16 patients (positive in 15 of 16 patients) [18]. Twenty-two patients also had positive SpIgE to omega-5 gliadin. All were counseled regarding treatment with wheat OIT. In all cases, families preferred and gave informed consent to wheat OIT.

\section{Protocol for wheat OIT}

The protocol of wheat OIT consisted of 3 phases. In phase I, a 3-day intensive care admission was required for 2 days of double-blind, placebo-controlled food challenge (DBPCFC) with wheat powder ( $10 \%$ wheat protein). We followed a protocol as outlined by Sampson et al. [19] with a starting dose of $1 \mathrm{mg}$ of wheat flour ( $0.1 \mathrm{mg}$ of wheat protein) and with log3 increment every 30 minutes until unequivocal reaction(s) occurred (i.e., eliciting dose [ED]) or a maximum dose of $300 \mathrm{mg}$ of wheat protein was reached. On the last day of phase I, the first OIT dose (1 dose below ED) was administered with premedications (cetirizine and montelukast). Carrying medium used was cow or soy milk. Reactions were recorded using a modification of World Allergy Organization (WAO) 2010 grading protocol [20]. Adrenaline was required for those who developed symptoms involving 2 organ systems. Patients were 
then discharged home with packages of premeasured wheat flour to be taken daily with premedication for 2 weeks. A 20\% dose increase of wheat flour were carried out in SAI at biweekly interval following with daily home administration. Wheat flour was switched to bread once a dose of $1.8 \mathrm{~g}$ of wheat protein was reached. The study was reviewed and approved the Internal Review Board Committee of the Bangkok Dusit Medical Services (BMC IRB 2018-07-023).

\section{Outcome measures}

The primary outcome measure chosen to represent the feasibility of the study was the retention rate of patients (\%) remained in the protocol during the entire 30-month period. Decision to discontinue OIT was made when a patient could not proceed on without severe adverse reaction. Secondary outcome measures included adverse reactions observed during DBPCFC and build-up phases both at SAI and at home, ED with its relationship to wheat SpIgE, maximum dose of wheat ingested and maximum duration of patients remained in the study.

\section{Statistics}

Descriptive statistics were used for analyzing demographic data and adverse reactions. Since age, SpIgE, ED were not normally distributed, median of these variables with ranges were used. Correlation between SpIgE and ED was calculated using a linear correlation module. Statistic program used throughout the study was IBM SPSS ver. 18.0 (IBM Co., Armonk, NY, USA).

\section{RESULTS}

Demographic data of the 26 patients (14 females and 12 males) studied were shown in Table 1. Most patients suffered from wheat allergy since very young age (median age of onset, 8 months; range, 3-13 months). Their median age at DBPCFC was 6 years (range, 2.6-14 years). Median SpIgE to wheat and omega-5 gliadin were $198 \mathrm{kU}_{\mathrm{A}} / \mathrm{L}$ (range, 1.19-1,628 kU $\mathrm{A}_{\mathrm{A}} / \mathrm{L}$ ) and $15.8 \mathrm{kU}_{\mathrm{A}} / \mathrm{L}$ (range, $0.77-200 \mathrm{kU}_{\mathrm{A}} / \mathrm{L}$ ), respectively. Fifteen out of 26 patients $(58 \%)$ had their wheat SpIgE over $100 \mathrm{kU}_{\mathrm{A}} / \mathrm{L}$ with 9 had level over $500 \mathrm{kU}_{\mathrm{A}} / \mathrm{L}$ (maximum, $1628 \mathrm{kU}_{\mathrm{A}} / \mathrm{L}$ ). Concomitant allergy to other foods was seen in 17 of 26 patients (65\%) (egg 6, seafood 2, soy 1 , peanut 1 , over 2 foods in 7 patients). Other allergy comorbidities included allergic rhinitis (76\%), asthma (15\%), and atopic dermatitis (30\%).

Table 1. Demographic data of patients included in the study (total $=26$ patients)

\begin{tabular}{lc}
\hline Variable & Value \\
\hline Sex, male:female & $12: 14$ \\
Age of onset WA $(\mathrm{mo})$ & $8(3-13)$ \\
Age at DBPCFC $(\mathrm{yr})$ & $6(2.8-14)$ \\
SplgE wheat $\left(\mathrm{KU}_{\mathrm{A}} / \mathrm{L}\right)$ & $198(1.19-1,628)$ \\
SplgE omega 5 gliain $\left(\mathrm{kU}_{\mathrm{A}} / \mathrm{L}\right)$ & $15.8(0.77-200)$ \\
Eliciting dose wheat protein $(\mathrm{mg})$ & $20(1-1,200)$ \\
Other allergy & $17(65.4)$ \\
$\quad$ Food allergy to other foods & $20(76.9)$ \\
$\quad$ AR & $4(15.4)$ \\
$\quad$ Asthma & $8(30.8)$ \\
$\quad$ Family history of atopy & $22(84.6)$ \\
\hline Values are presented as median (range) or number $(\%)$. & \\
WA, wheat allergy; DBPCFC, double-blind, placebo-controlled food challenge; SpIgE, serum specific IgE; AR, \\
allergic rhinitis.
\end{tabular}


Table 2. Observed adverse reactions after wheat OIT during DBPCFC and build-up phases (total $n=26$ patients)

\begin{tabular}{|c|c|c|}
\hline Variable & DBPCFC & Build-up phase \\
\hline No. of patients (cases) & 26 & 13 \\
\hline Frequency of reactions (times) & 26 & 55 \\
\hline No. of adrenaline injections (times) & 17 & 6 \\
\hline \multicolumn{3}{|l|}{ System involvement (times) } \\
\hline Skin (S) only & 4 & 35 \\
\hline Respiratory (R) only & 0 & 2 \\
\hline Gastrointestinal (G) only & 1 & 3 \\
\hline Neurological (N) only & 0 & 0 \\
\hline \multicolumn{3}{|l|}{ More than 2-system involvement } \\
\hline $\mathrm{S}+\mathrm{R}$ & 7 & 9 \\
\hline $\mathrm{S}+\mathrm{G}$ & 1 & 2 \\
\hline $\mathrm{S}+\mathrm{N}$ & 2 & 0 \\
\hline $\mathrm{R}+\mathrm{G}$ & 1 & 2 \\
\hline $\mathrm{S}+\mathrm{R}+\mathrm{G}$ & 5 & 1 \\
\hline $\mathrm{S}+\mathrm{R}+\mathrm{N}$ & 3 & 1 \\
\hline $\mathrm{S}+\mathrm{G}+\mathrm{N}$ & 1 & 0 \\
\hline $\mathrm{S}+\mathrm{R}+\mathrm{G}+\mathrm{N}$ & 1 & 0 \\
\hline
\end{tabular}

Description of reactions: skin reactions = maculopapular rash, urticaria, flushing, angioedema; respiratory = nasal congestion, rhinorrhea, cough, wheeze; gastrointestinal = abdominal pain, nausea, vomiting, diarrhea; neurological $=$ alteration of consciousness, change of behavior, drowsiness.

OIT, oral immunotherapy; DBPCFC, double-blind, placebo-controlled food challenge.

All patients developed reactions during DBPCFC ( 4 with modified WAO grade I, 9 with grade II and 13 with grade III). Table 2 showed details of reactions during both DBPCFC and buildup phases. Common reactions observed were skin involvement followed by respiratory and gastrointestinal systems. Majority of patients developed reactions in more than one body system ( 21 of 26 patients). Adrenaline was used in 17 of 26 patients (65\%) during DBPCFC. Median ED dose was $20 \mathrm{mg}$ of wheat protein. In Fig. 1, it is quite apparent that there was no correlation between $\mathrm{ED}$ and level of wheat $\operatorname{SpIgE}(r=-0.26, p=0.182)$. In the build-up phase, 13 of 26 patients $(50 \%)$ developed reactions of which requiring 6 administrations of adrenaline.

Three patients dropped out from the protocol during the 30-month observation period (retention rate of $88 \%$ ). Time of drop out was at 3 weeks (severe eczema - 1 patient), 4 weeks (persistent vomiting -1 patient), and 110 weeks (lost to follow-up -1 patient) after initiation of OIT. At the end of the study, 17 of 26 were on the build-up phase while 6 patients reached target doses ( 2 patients -1 slice of bread/day, 4 patients increased maintenance dose voluntarily to 2-3 slices/day). The longest duration of patient remained in the study was 127 weeks.

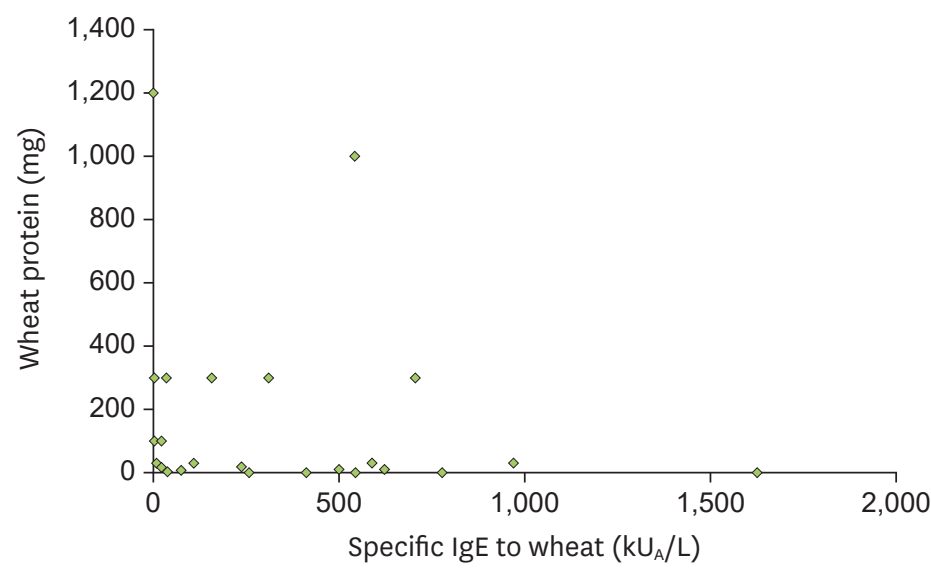

Fig. 1. Correlation between wheat specific IgE to and eliciting dose $(r=-0.26, p=0.182)$. 


\section{DISCUSSION}

We demonstrated that our new relatively low-dose wheat OIT protocol could be carried out with a high retention rate $(88 \%)$ during the 30 -month period in this group of patients. However, a high rate of adverse reactions was noted during DBPCFC (100\%) and build-up phases ( 13 of $26,50 \%$ ). Rates of adverse reactions in previous reports were much lower than in our study despite their much higher targeted OIT doses. For example, Sato et al. [15] reported 6 of 18 patients (35\%) developed reactions needing adrenaline during challenge phase. A multicenter trial of wheat OIT from USA reported adverse reactions of $15 \%$ with severe reactions requiring adrenalin despite their high maintenance dose of $4.4 \mathrm{~g}$ of wheat protein [16]. More recently, Makita et al. [21] using a similar protocol as Sato et al. [15] observed no severe reactions required adrenaline during their rush OIT phase. However, a study from Finland reported moderate to severe reactions in $60 \%$ of their patients [17]. Differences in rate of adverse reactions noted among these studies could be due to differences in patients' degree of wheat sensitivities, source of wheat used for OIT, OIT protocol (and flexibility of protocol), premedication, and cofactors such as exercise and infection. Since we were able to dilute patients' sera to know their exact wheat SpIgEs, we tended to advise OIT to those with very high levels ( 15 of 26 had level over $100 \mathrm{kU}_{\mathrm{A}} / \mathrm{L}$ ). This could be the most important reason for high rates of adverse reactions in our study as well as in the Kulmala's study although further investigation is needed to clarify this contention.

Retention rate of patients in our study was high (88\%). This is comparable to the rate observed by Sato et al. [15] from Japan (94\%). It is difficult to calculate such rate from the study of Nowak et al. [16] but most of their selected patients were able to reach the maximum OIT dose. On the contrary, the Finnish report showed only $57 \%$ retention rate [17]. Since we were not stringent in the criteria of discontinuation in our real-life OIT practice, OIT was continued among several children with adverse reactions whom parents requested OIT continuation. Some of these patients could have been excluded out from OIT schedule by investigational criteria. Such exclusion could have even lowered our retention rate further. One prognostic factor for predicting adverse reactions and dropping out/exclusion could be high level of SpIgE to wheat. In our analysis (data available upon request), there was no relationship between grade of reactions developed during the build-up phase and level of wheat SpIgE in this patient group.

Since reactions noted in DBPCFC were severe ( $84 \%$ had reactions in WAO grade II and III with $65 \%$ needing adrenaline injections)., it is thus prudent to carry out such challenge in the intensive care unit. Severe reactions were also observed in build-up phase and adrenaline was needed in 6 occasions. Skin manifestation was the most common system involved and 15 of $26(57 \%)$ had reactions in 2 or more body systems.

It should be pointed out that $\mathrm{ED}$ in this study was low, i.e., median of $200 \mathrm{mg}$ of wheat powder (20 mg of wheat protein). Other studies reported varying EDs (range, 43-450 mg) [8, 14-17]. This is not unexpected since patients selected for various studies had different degree of wheat sensitivities. In fact, a negative but nonsignificant relationship between wheat SpIgE and ED dose was observed in our study. Taken together, we feel strongly that the starting dose for DBPCFC should be equal to or lower than $1 \mathrm{mg}$ of wheat protein for patients with high degree of wheat allergy.

The dose of wheat protein chosen for maintenance phase in this study (1.5-g wheat protein - one slice of bread) is low compared to a much higher maintenance dose in other studies 
[14-16]. Most studies selected amount of wheat protein contained in 2-3 slices of bread (i.e., $4.4-5.2 \mathrm{~g}$ ) to be their maintenance doses. Aim of OIT is a very important consideration in choosing target doses of OIT. For instance, if ones aim to avoid reactions after minute exposure to wheat, maintenance OIT dose could be set to a much lower dose such as $100-400 \mathrm{mg}$ of wheat protein (as contained in reasonable volume of seasoning sauce for daily cooking). Such lower maintenance dose is a much readily feasible in real-life situation (i.e., low-dose OIT). This is perhaps desirable for parents to allow cooking more palatable foods for their children. For those patients desired to consume normal serving of wheat-containing food, higher maintenance dose of wheat OIT should be set accordingly. Additionally, lowdose OIT should be associated with less adverse reactions than conventional OIT [22]. We are unable to study sustained unresponsiveness (ability to consume food ad libitum) in our study due to a short duration of our study. In the Nowak et al. [16], after 2 years of treatment, almost half of their patients lost their tolerance after discontinuing maintenance dose for only 8-10 weeks. Similarly, allergic symptoms recurred as early as 1 month after passing the final OFC in the study of Makita et al. [21]. Thus, in order to achieve sustained unresponsiveness, wheat OIT may require a longer than 2 years maintenance period as suggested in studies with egg OIT [23].

Short comings of this study are small number of patients, lack of controls, and short duration of follow-up. The study, however, was designed only to learn about the feasibility and safety of this new OIT protocol. Moreover, it is performed in a real-life allergy practice and thus could represent a more realistic picture than in a strict investigational environment. It is possible that with the extension of the study period, more clarifications on retention rate, rate of adverse reactions, length of maintenance, and even sustained unresponsiveness could be examined further.

In conclusion, we, herein, reported that the new 3-phase wheat OIT protocol can be used for highly sensitized wheat allergic patients. However, there were high rates of adverse reactions and thus, such therapy should be performed by professionals with thorough knowledge on natural history of wheat allergy and also with knowledge in the treatment of anaphylaxis. Close home follow-up care is needed to monitor adverse reactions during the build-up phases to ensure safety of these patients.

\section{ACKNOWLEDGEMENTS}

The authors wish to thank SAI staff (Ms Nichamon Muangnue, Ms Thitirat Weeravejsukit, Ms Natchaya Muangchan, Ms Sunaree Losanthea, Ms Nipawan Vilathorn, and Ms Kwanruan Srichaiya) for their excellent contribution in the care for our patients. In addition, we thank all our patients and their families to participate in this study.

\section{REFERENCES}

1. Tham EH, Leung ASY, Pacharn P, Lee S, Ebisawa M, Lee BW, Wong GWK; APAPARI Anaphylaxis Study Group. Anaphylaxis - lessons learnt when East meets West. Pediatr Allergy Immunol 2019;30:681-8. PUBMED | CROSSREF

2. Imamura T, Kanagawa Y, Ebisawa M. A survey of patients with self-reported severe food allergies in Japan. Pediatr Allergy Immunol 2008;19:270-4.

PUBMED | CROSSREF 
3. Siripipattanamongkol N, Vichyanond P, Jirapongsananuruk O, Veskitkul J, Visitsunthorn N, Pacharn P. Age of resolution from IgE-mediated wheat allergy. Asian Pac J Allergy Immunol 2017;35:113-7. PUBMED

4. Pacharn P, Siripipattanamongkol N, Veskitkul J, Jirapongsananuruk O, Visitsunthorn N, Vichyanond P. Successful wheat-specific oral immunotherapy in highly sensitive individuals with a novel multirush/ maintenance regimen. Asia Pac Allergy 2014;4:180-3. PUBMED | CROSSREF

5. Lee SY, Ahn K, Kim J, Jang GC, Min TK, Yang HJ, Pyun BY, Kwon JW, Sohn MH, Kim KW, Kim KE, Yu J, Hong SJ, Kwon JH, Kim SW, Song TW, Kim WK, Kim HY, Jeon YH, Lee YJ, Lee HR, Kim HY, Ahn Y, Yum HY, Suh DI, Kim HH, Kim JT, Kim JH, Park YM, Lee S; Korean Academy of Pediatric Allergy and Respiratory Diseases Food Allergy and Atopic Dermatitis Study Group. A multicenter retrospective case study of anaphylaxis triggers by age in Korean children. Allergy Asthma Immunol Res 2016;8:535-40. PUBMED | CROSSREF

6. Zhu YQ, Wang DQ, Liu B, Hu Y, Shen YY, Xu JH, Tang H. Wheat-dependent exercise-induced anaphylaxis in Chinese people: a clinical research on 33 cases with antigenic analysis of wheat proteins. Clin Exp Dermatol 2020;45:56-62. PUBMED | CROSSREF

7. Jiang N, Yin J, Wen L, Li H. Characteristics of anaphylaxis in 907 Chinese patients referred to a tertiary allergy center: a retrospective study of 1,952 episodes. Allergy Asthma Immunol Res 2016;8:353-61. PUBMED | CROSSREF

8. Khayatzadeh A, Gharaghozlou M, Ebisawa M, Shokouhi Shoormasti R, Movahedi M. A safe and effective method for wheat oral immunotherapy. Iran J Allergy Asthma Immunol 2016;15:525-35. PUBMED

9. Smit DV, Cameron PA, Rainer TH. Anaphylaxis presentations to an emergency department in Hong Kong: incidence and predictors of biphasic reactions. J Emerg Med 2005;28:381-8. PUBMED | CROSSREF

10. Liew WK, Chiang WC, Goh AE, Lim HH, Chay OM, Chang S, Tan JH, Shih E, Kidon M. Paediatric anaphylaxis in a Singaporean children cohort: changing food allergy triggers over time. Asia Pac Allergy 2013;3:29-34. PUBMED | CROSSREF

11. Srisuwatchari W, Vichyanond P, Jirapongsananuruk O, Visitsunthorn N, Pacharn P. Characterization of children with IgE-mediated wheat allergy and risk factors that predict wheat anaphylaxis. Asian Pac J Allergy Immunol 2020 Mar 29. [Epub] DOI: 10.12932/AP-130919-0645. PUBMED | CROSSREF

12. Keet CA, Matsui EC, Dhillon G, Lenehan P, Paterakis M, Wood RA. The natural history of wheat allergy. Ann Allergy Asthma Immunol 2009;102:410-5. PUBMED | CROSSREF

13. Koike Y, Yanagida N, Sato S, Asaumi T, Ogura K, Ohtani K, Imai T, Ebisawa M. Predictors of persistent wheat allergy in children: a retrospective cohort study. Int Arch Allergy Immunol 2018;176:249-54. PUBMED | CROSSREF

14. Rodríguez del Río P, Díaz-Perales A, Sanchez-García S, Escudero C, do Santos P, Catarino M, Ibañez MD. Oral immunotherapy in children with IgE-mediated wheat allergy: outcome and molecular changes. J Investig Allergol Clin Immunol 2014;24:240-8. PUBMED

15. Sato S, Utsunomiya T, Imai T, Yanagida N, Asaumi T, Ogura K, Koike Y, Hayashi N, Okada Y, Shukuya A, Ebisawa M. Wheat oral immunotherapy for wheat-induced anaphylaxis. J Allergy Clin Immunol 2015;136:1131-3.e7. PUBMED | CROSSREF

16. Nowak-Węgrzyn A, Wood RA, Nadeau KC, Pongracic JA, Henning AK, Lindblad RW, Beyer K, Sampson HA. Multicenter, randomized, double-blind, placebo-controlled clinical trial of vital wheat gluten oral immunotherapy. J Allergy Clin Immunol 2019;143:651-61.e9. PUBMED | CROSSREF

17. Kulmala P, Pelkonen AS, Kuitunen M, Paassilta M, Remes S, Schultz R, Dunder T, Turunen S, Mäkelä MJ. Wheat oral immunotherapy was moderately successful but was associated with very frequent adverse events in children aged 6-18 years. Acta Paediatr 2018;107:861-70. PUBMED | CROSSREF

18. Pacharn P, Kumjim S, Tattiyapong P, Jirapongsananuruk O, Piboonpocanun S. Identification of wheat sensitization using an in-house wheat extract in Coca-10\% alcohol solution in children with wheat anaphylaxis. Asian Pac J Allergy Immunol 2016;34:153-8. PUBMED 
19. Sampson HA, Gerth van Wijk R, Bindslev-Jensen C, Sicherer S, Teuber SS, Burks AW, Dubois AE, Beyer K, Eigenmann PA, Spergel JM, Werfel T, Chinchilli VM. Standardizing double-blind, placebo-controlled oral food challenges: American Academy of Allergy, Asthma \& Immunology-European Academy of Allergy and Clinical Immunology PRACTALL consensus report. J Allergy Clin Immunol 2012;130:1260-74. PUBMED | CROSSREF

20. Cox LS, Sanchez-Borges M, Lockey RF. World Allergy Organization systemic allergic reaction grading system: is a modification needed? J Allergy Clin Immunol Pract 2017;5:58-62.e5. PUBMED | CROSSREF

21. Makita E, Yanagida N, Sato S, Asaumi T, Ebisawa M. Long-term prognosis after wheat oral immunotherapy. J Allergy Clin Immunol Pract 2020;8:371-4.e5. PUBMED | CROSSREF

22. Okada Y, Yanagida N, Sato S, Ebisawa M. Better management of wheat allergy using a very low-dose food challenge: A retrospective study. Allergol Int 2016;65:82-7. PUBMED | CROSSREF

23. Kim EH, Jones SM, Burks AW, Wood RA, Sicherer SH, Leung DYM, Henning AK, Lindblad RW, Dawson P, Keet C, Scurlock AM, Plaut M, Sampson HA. A 5-year summary of real-life dietary egg consumption after completion of a 4-year egg powder oral immunotherapy (eOIT) protocol. J Allergy Clin Immunol 2020;145:1292-5.e1.

PUBMED | CROSSREF 